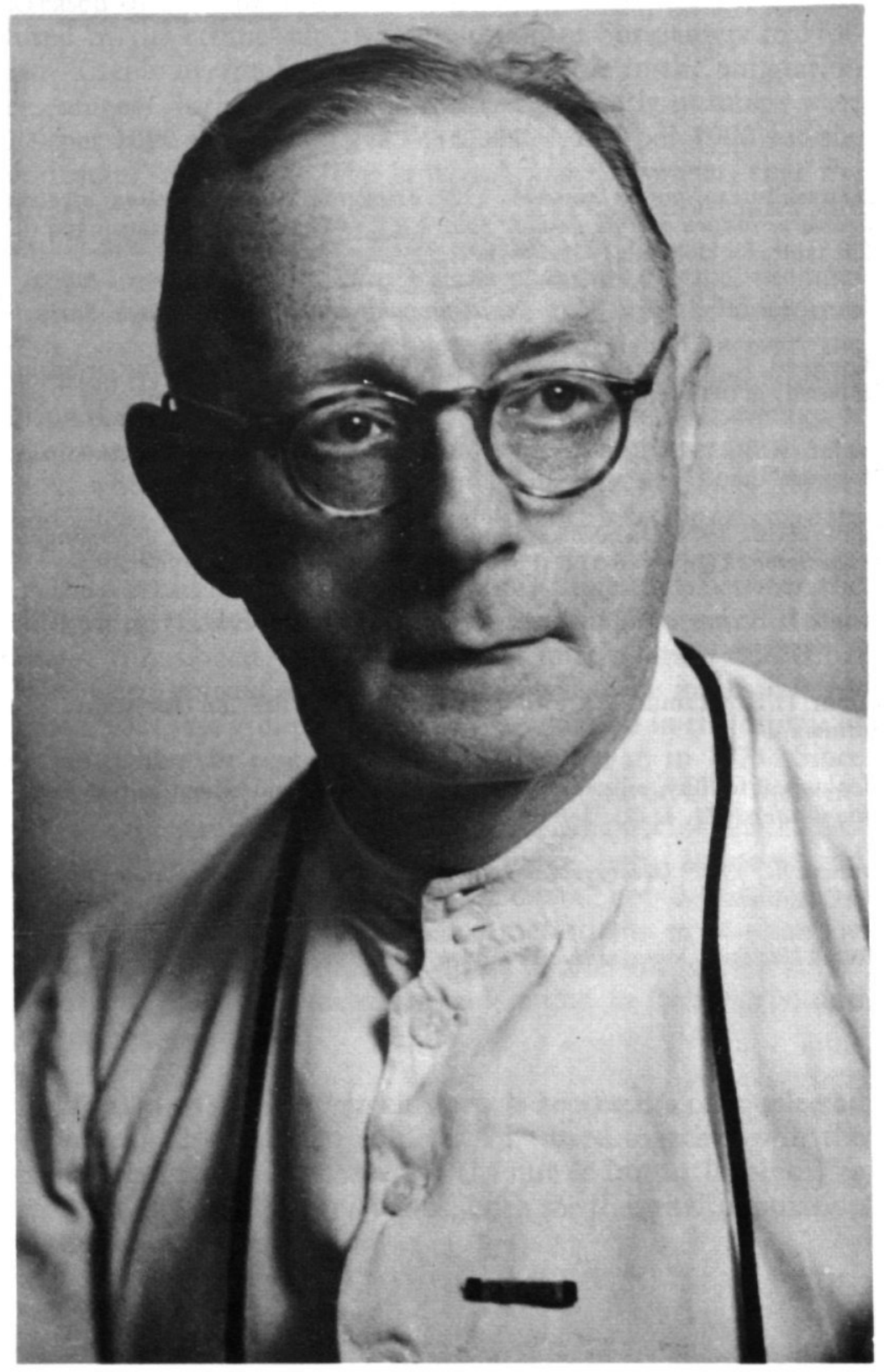

fi. In. Realine Jansen. 


\section{IN MEMORIAM FRATER M. REALINO}

Op 22 februari 1977 overleed op 87-jarige leeftijd in het Fraterhuis Johannes Zwijsen te Tilburg Frater M. Realino-Janssen. Hij was een zo groot en trouw vriend van hen die zich met het wetenschappelijk onderzoek van de Nederlandse Antillen bezig hielden, en heeft daarbij op Curaçao zo veel gedaan om kennis en liefde voor eigen land te bevorderen, dat het niet onjuist lijkt in de N.W.I.G. voor zijn leven en werken enige aandacht te vragen.

Frederikus Johannes Antonius Janssen werd op 18 november 1889 te Zwolle geboren. Hij was de oudste zoon van Jacobus Theodorus Janssen (1859-1951) die van zijn 14de tot zijn 28ste jaar als matroos-zeilmaker vele zeeën bevoer en daarbij ook Curaçao leerde kennen.

Toen Frits op zesjarige leeftijd voor de eerste keer naar school was geweest - waarbij hij de boeken van het hoofd Frater Fulgentius - Wulfers had mogen dragen - zei hij: 'Ik wil óók frater worden', en, toen zijn moeder wat aarzelend keek: 'Nu, ik heb het al lang met frater Fulgentius in orde gemaakt.'

En zo gebeurde het ook. Frits ging op zijn dertiende jaar naar de Kweekschool, kreeg op 25 april 1908 zijn onderwijzersbevoegdheid, en trad op 31 mei van ditzelfde jaar in de Congregatie der Fraters van Onze Lieve Vrouw Moeder van Barmhartigheid te Tilburg, waarbij hij de kloosternaam Realino ontving.

Van 1 mei 1908 tot 1 februari 1915 stond hij achtereenvolgens in vier scholen in Tilburg voor de klas, en daarna tot 1 januari 1917 in 's-Hertogenbosch. Drie maanden later vertrok hij naar Curaçao, waar hij tot 19 februari 1960 bleef.

Frater Realino was een studiehoofd. $\mathrm{Na}$ een akte Duits L.O. (in 1913) behaalde hij nog een diploma voor Vrije en Ordeoefeningen (1914), de hoofdakte (1916) en (in 1923, op Curaçao) de akte Spaans L.O.

Op Curaçao werd Realino, reeds een goede maand na aankomst, benoemd tot hoofd van het St. Thomas-College, een functie welke hij echter slechts tot december 1919 heeft vervuld. 
In deze tijd - toen de onderwijsmogelijkheden op Curaçao nog niet zo heel groot waren - wist hij zich door zelfstudie zo te bekwamen dat hij in staat was op wetenschappelijk gebied twee leerboeken samen te stellen, speciaal bestemd voor het Antilliaanse onderwijs, hetgeen toen stellig iets bijzonders was. In 1929 verscheen er een aardrijkskunde-boekje over de Nederlandse Antillen en de overige eilanden van het Caraïbische Zee, dat in 1931 en 1938 in nieuwe bewerkingen werd herdrukt. In 1935 volgde een Plantkunde van Curaçao, dat in 1947 een tweede druk beleefde. Daarbij bouwde hij naarstig voort aan een bibliotheek van geschriften met betrekking tot West-Indië, vooral op historisch gebied, in het bijzonder gedurende de laatste tien jaren op Curaçao toen hij als archivaris en bibliothecaris op het St. Thomas-College werkzaam was. (Na de opheffing van het St. Thomas-College in augustus 1970, werd deze 'Westindische Bibliotheek' als aparte eenheid opgenomen in de Centrale Bibliotheek van het Fraterhuis te Tilburg.)

Frater Realino werd reeds in 1945 lid van de eerder in dat jaar opgerichte 'Natuurwetenschappelijke Studiekring voor Suriname en de Nederlandse Antillen' en was in 1954 medeoprichter van de 'Natuurwetenschappelijke Werkgroep Nederlandse Antillen'. Vele jaren lang was hij Regent van 'Het Curaçaosche Museum.' $\mathrm{Bij}$ dit alles bleef hij een bij uitstek rustige en bescheiden figuur, zwijgzaam van aard, die zich nimmer op de voorgrond plaatste. Niemand was dan ook meer verwonderd dan hij, toen hij — om zijn grote verdiensten op onderwijsgebied - op 30 april 1949 werd benoemd tot Ridder in de Orde van Oranje-Nassau.

Met zijn grote kennis van planten en dieren was Realino toch geen veldbioloog; daarvoor zat zijn verlangen naar de studeerkamer te diep en was zijn belangstelling voor ook andere zaken te groot. Van zijn behoefte om zijn kennis van de eilanden te blijven toetsen aan de ontwikkelingen van de wetenschap getuigen de herziene uitgaven van zijn beide schoolboeken. Zo werden in de derde druk van zijn aardrijkskundeboek (wel enigszins ten koste van de homogeniteit van de inhoud) tal van nieuwe gegevens verwerkt, als resultaat van zijn ontmoeting met de leden van de Utrechtse geologische excursie, in 1930 door prof. dr. L.M.R. Rutten naar de Antillen ondernomen. 
Deze ontmoeting is niet alleen voor Frater Realino van betekenis geweest. Nog vele keren hebben deelnemers aan deze expeditie, bij herhaalde bezoeken aan Curaşao, de weg naar de koele ontvangkamer van het Sint Thomascollege weten te vinden, om te kunnen praten over de vele dingen waarin men samen belangstelde, onder het genot van een 'potteke bier' en een dikke sigaar van Elisabeth Bas - de vrouw die binnen deze muren het meeste welkom was.

$\mathrm{Na}$ zijn terugkeer in Nederland is Frater Realino 'op pensioen' gegaan. Hij heeft toen nog korte tijd gewerkt in de administratie van de centrale studiebibliotheek. Daarna heeft hij alle foto's van de Nederlandse Antillen, die op het archief in grote hoeveelheid aanwezig waren, geordend en beschreven, en vervolgens ook nog die van Suriname en andere gebieden.

De laatste jaren van zijn leven bracht Realino door met studeren. Hij vertaalde veel Spaanse artikelen en maakte daarover massa's aantekeningen - zo'n driehonderd cahiers duidelijk, regelmatig handschrift - in de hoop dat deze later nog eens van nut zouden kunnen zijn.

Hoewel moeilijk ter been en gehinderd door een toenemende doofheid, had hij vrede met zijn oude dag, waarin - tot zijn grote vreugde - het roken van sigaren hem nimmer werd ontzegd.

Realino's plechtige uitvaart in de Kapel van het Moederhuis in Tilburg - waarbij Mgr. H.J.C.M de Cocq het woord voerde was een waardig afscheid van iemand die in harmonie met zijn omgeving lange tijd op Curaçao had doorgebracht en daarbij niet anders dan vrienden had ontmoet.

Het lichaam werd begraven op Huize Steenwijk te Vught, 22 februari 1977. 


\section{LIJST VAN PUBLICATIES \\ in chronologische volgorde}

Fr. M. Realino, 1929, Aardrijkskunde. De eilanden van Nederlandsch West-Indië. De overige eilanden van West-Indië. Venezuela en Columbia. Uitgave van het St. Thomas-College, Curaşao. Drukkerij van het R.K. Jongensweeshuis, Tilburg; $120 \mathrm{blz} .21 \times 14 \mathrm{~cm}$, (69) afb. ('dit schoolboekje is de tweede, vermeerderde druk van: Aardrijkskunde I. De kolonie Curafao en de verdere West-Indische eilanden. 1926. Het werd in 1926 uitgegeven voor het R.K. Lager Onderwijs door Fr. M. Hermenigild ..., $18 \mathrm{blz}$. zonder afb.)

Fr. M. Realino, 1931. Onze eilanden in Nederlandsch West-Indië en de overige eilanden van de Caraïbische Zee, Venezuela en Columbia. Tweede herziene druk. Idem; $170 \mathrm{blz}$., (107) afb.

(1934). Het stadsdistrict Willemstad. Schaal $1: 20.000$. R.K. Boekhandel St. Augustinus, Curaçao; 2e druk, kaart $22 \times 47 \mathrm{~cm}$.

Frater M. Realino, 1934. Curaqao (Algemene beschrijving). Natuwr en Mensch 54, no. 4-5 (Curaçao nummer), blz. 13-17, (3) afb.

Fr. M. Realino, 1935. Plantkunde van Curagao voor M.U.L.O. R.K. Boekhandel 'St. Augustinus', St. Thomas-College, Curafao; $133 \mathrm{blz} .23 \times 15 \mathrm{~cm},(78) \mathrm{afb}$. (foto's van fr. M. Arnoldo-Broeders; verschenen in maart 1936).

Fr. M. Realino, 1936. Vragenboekje bij 'Plaintkunde van Curagao... '. Idem; 40 blz.

Fr. M. Realino, 1938. De Nederlandse Antillen en de overige eilanden van de Caraïbische Zee, Venezuela en Colombia. Derde herziene druk. Idem; 214 blz., $(163+1) \mathrm{afb}$.

Fr. M. Realino, 1940. Schoolatlasje behorend bij De Nederlandse Antillen... Idem; $32 \mathrm{blz}$.

Fr. M. Realino, 1941. Vragenboekje bij 'De Nederlandse Antillen...' 2e druk. R.K. Boekhandel 'St. Augustinus' Curaçao; $26(+6)$ blz. $20 \times 14 \frac{11 / 2}{\mathrm{~cm}}$.

(1943?). MULO-dierkunde. (Curaşao), $(34+28)$ blz. $18 \times 22 \mathrm{~cm}$ stencil met afb. Fr. M. Realino, 1947. Plantkunde van Curagao voor M.U.L.O. Tweede druk. Idem; 188 blz., $209 \mathrm{afb}$.

Fr. M. Realino, 1948. Vragenboekje bij de tweede druk van Plantkunde... Idem; $38 \mathrm{blz}$. 
Frater Realino, 1948. Het land; flora; fauna. Oranje en de zes Caraïbische parelen, p. 63-70.

Fr. Realino, 1949. Aruba. De Katholieke Encycoplaedie, Tweede druk, deel 3, kolom 142-150, 2 kaarten, 4 foto's op 2 platen buiten de tekst.

Realino Janssen, 1950. Benedenwindse Eilanden. Kath. Enc. 4, kol. 524-529, 2 krtn.

Realino Janssen, 1950. Bonaire. Kath. Enc. 5, kol. 604-611, 2 krtn, 4 fot. op 2 pl.

Fr. Realino, 1950. Bovenwindse Eilanden. Kath. Enc. 5, kol. 894-899, 1 krt.

Realino Janssen, 1951. Curaçao. Kath. Enc. 8, kol. 203-221, 4 krtn, 9 fot. op 4 pl.

Realino Janssen, 1954. St. Eustatius. Kath. Enc. 21, kol. 339-340, 2 krtn, 2 fot. op 1 pl.

Realino Janssen, 1954. Sint Maarten. Kath. Enc. 21. $351-352$ (+ 355), 2 krtn, 1 foto.

Realino Janssen / Westermann, 1954. Saba. Kath. Enc. 21, kol. 369-370, 1 krt, 1 foto.

Fr. M. Realino Janssen, 1961. In memoriam Frater M. Radulphus, 1869-1961. Nieuwe West-Indische Gids 41, blz. 61-64, portret buiten de tekst.

Bij gelegenheid van Fr. Realino's 86ste verjaardag verscheen er een artikel in $\mathrm{La}$ Union (12 Nov. '75). Na zijn overlijden verschenen er stukjes van de hand van fr. Wibertus Rietman in de Beurs, de Amigoe (23 febr.) en La Union (2 maart).

De schrijver van dit artikel is de heer A.F. Janssen (jongere broer van Fr. Realino) en Fr. Caesario Peters (archivaris van het Fraterhuis in Tilburg) dankbaar voor het verstrekken van enkele gegevens welke in dit In Memoriam konden worden verwerkt.

P. WAGENAAR HUMMELINCK 